\title{
Au Nanoparticle Templated Synthesis of pNIPAm Nanogels
}

Neetu Singh and L. Andrew Lyon*

School of Chemistry and Biochemistry \& Petit Institute for Bioengineering and Bioscience, Georgia Institute of Technology, Atlanta, Georgia 30332-0400 (USA)

\section{Supporting Information}

Figure S1. AFM images and corresponding line profiles of $1 \mathrm{mM}$ pNIPAm-co-AAc nanogels on a glass substrate (a) before and (b) after etching of the gold template cores, and on aminosilane functionalized glass substrate (c) before and (d) after etching of the gold cores.
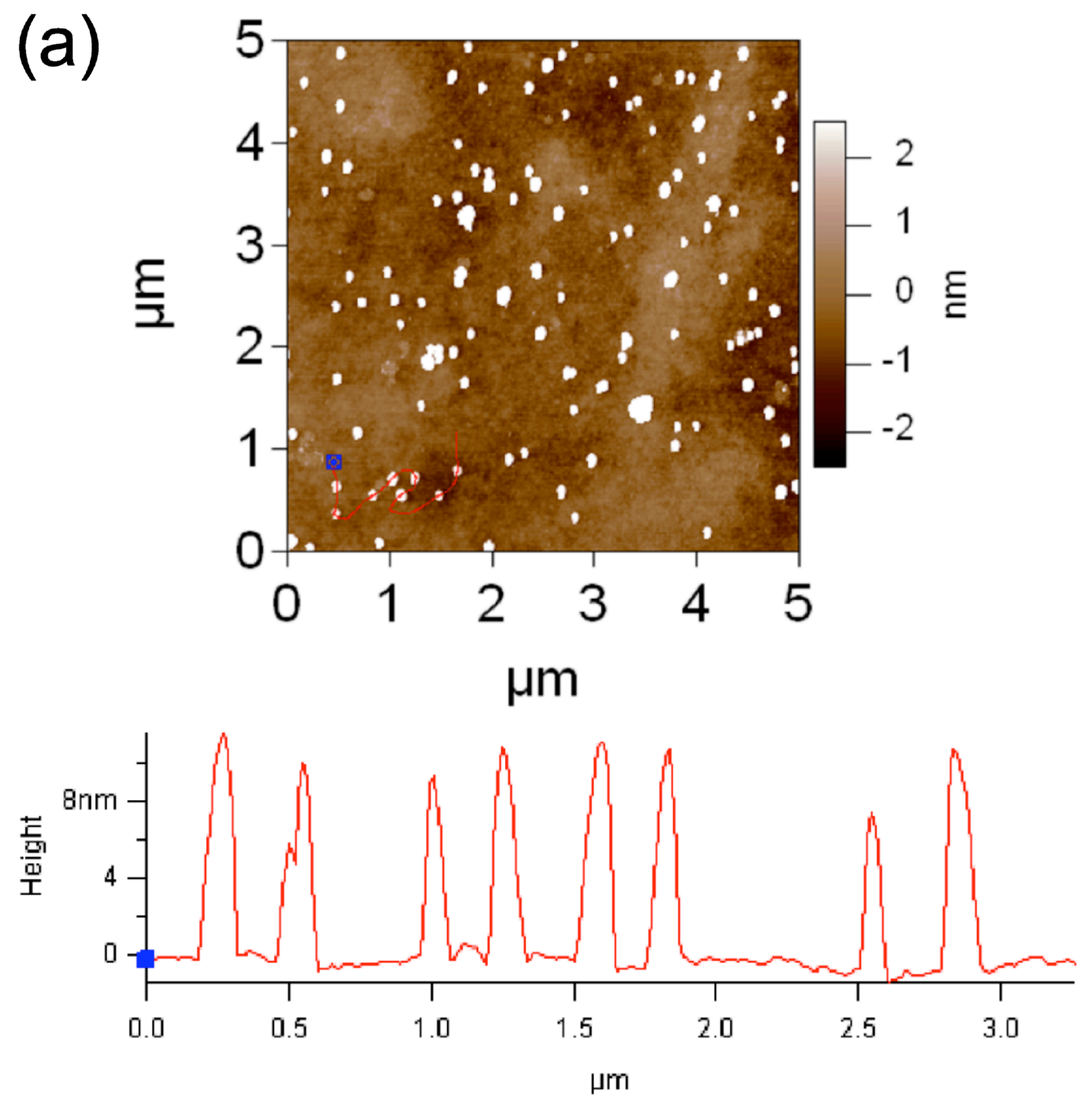
(b)
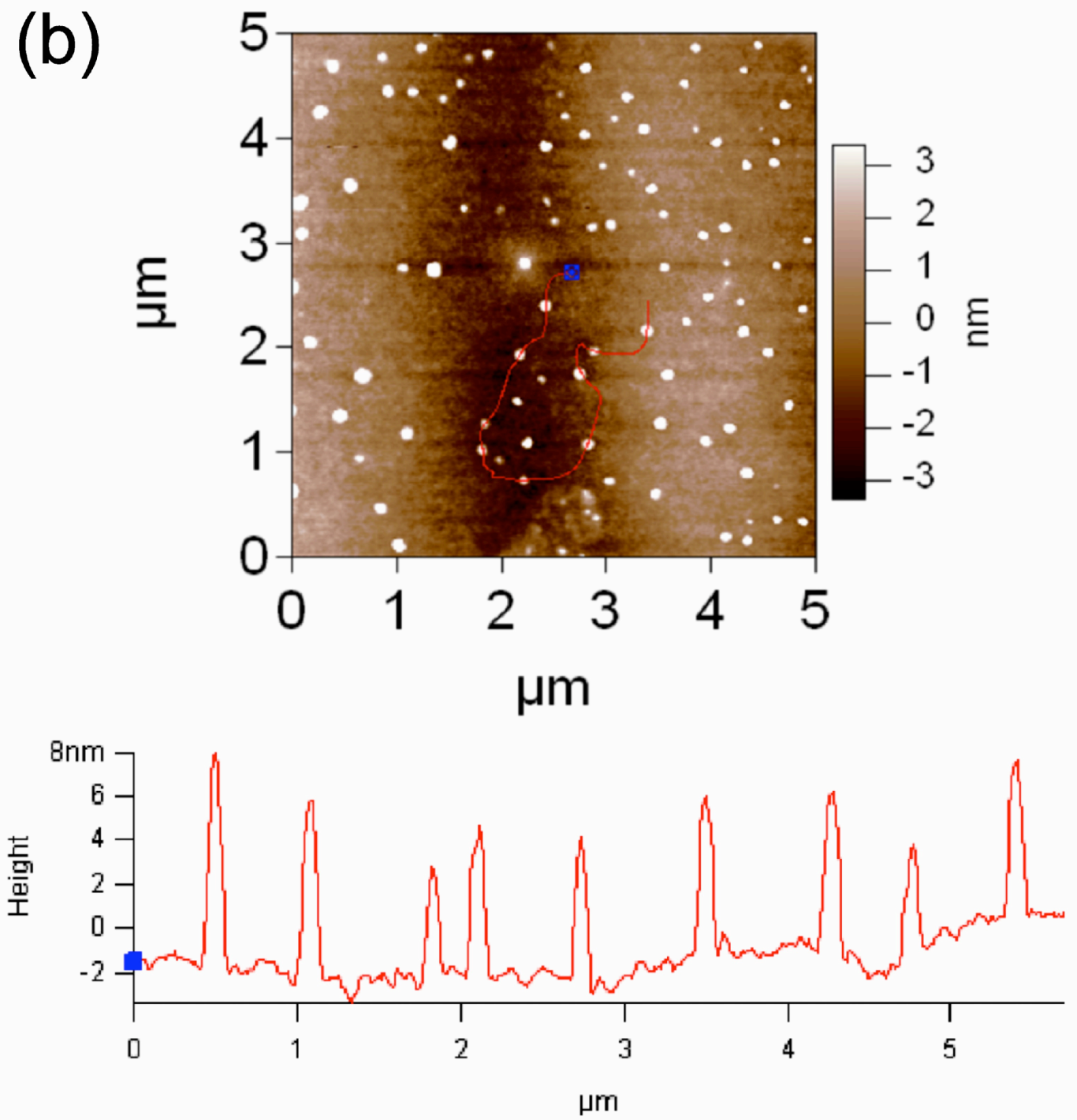
(c)

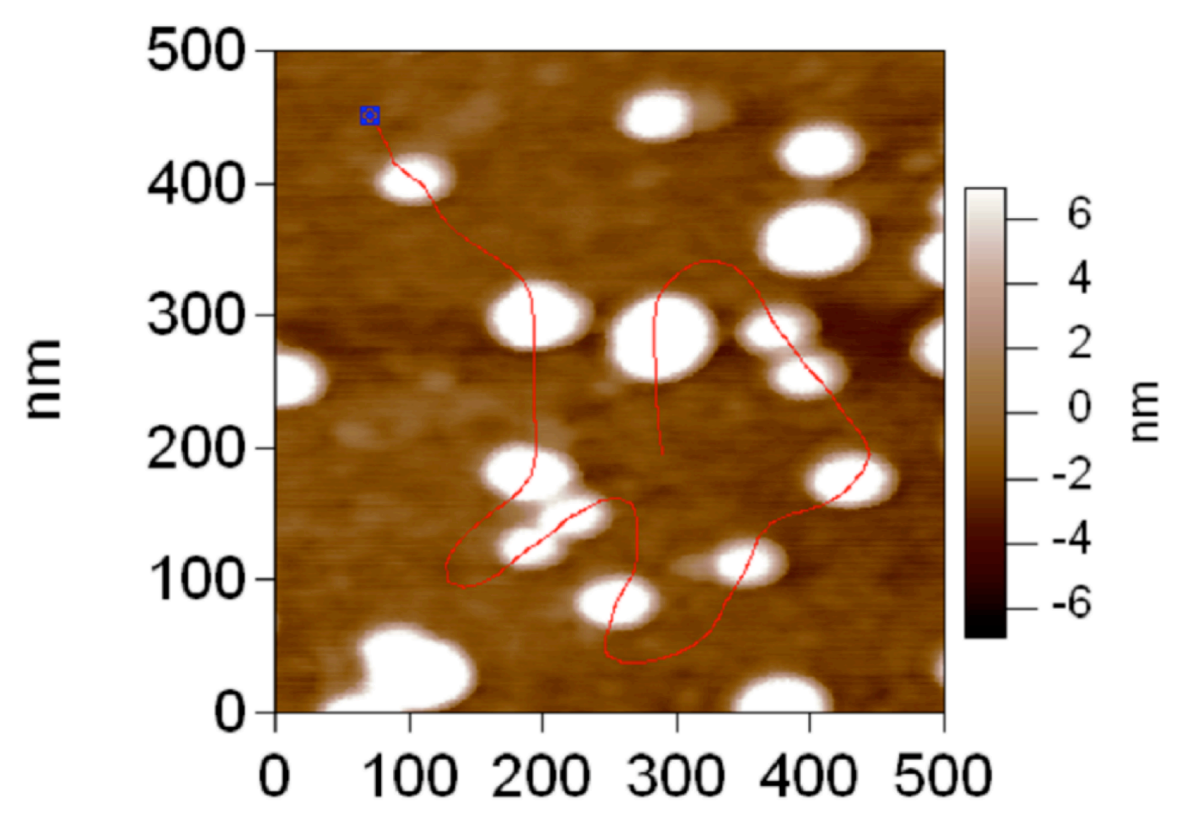

$\mathrm{nm}$

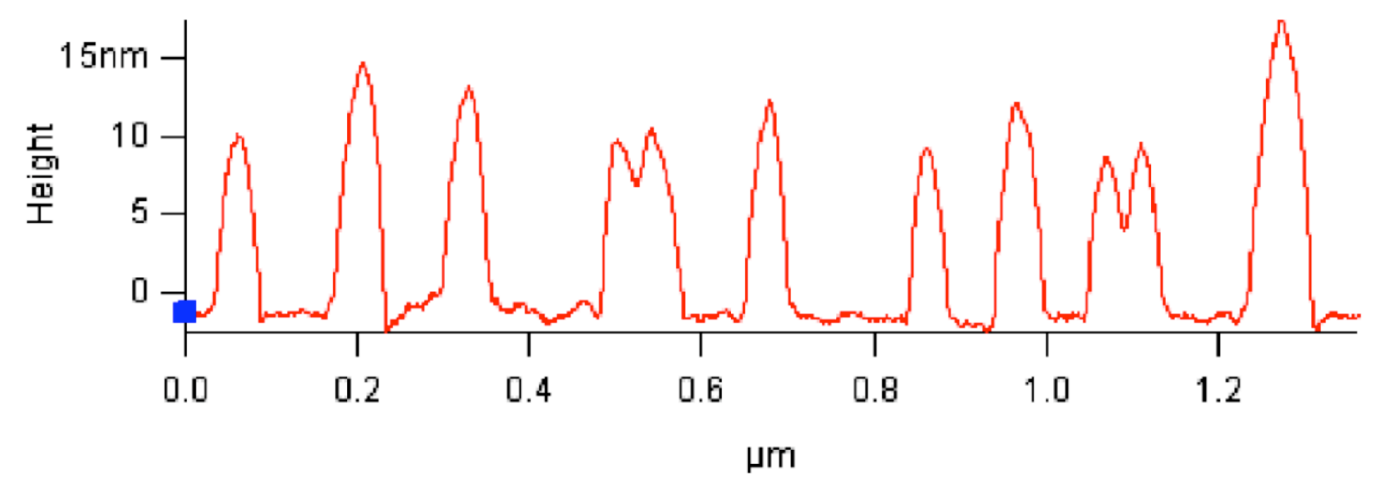



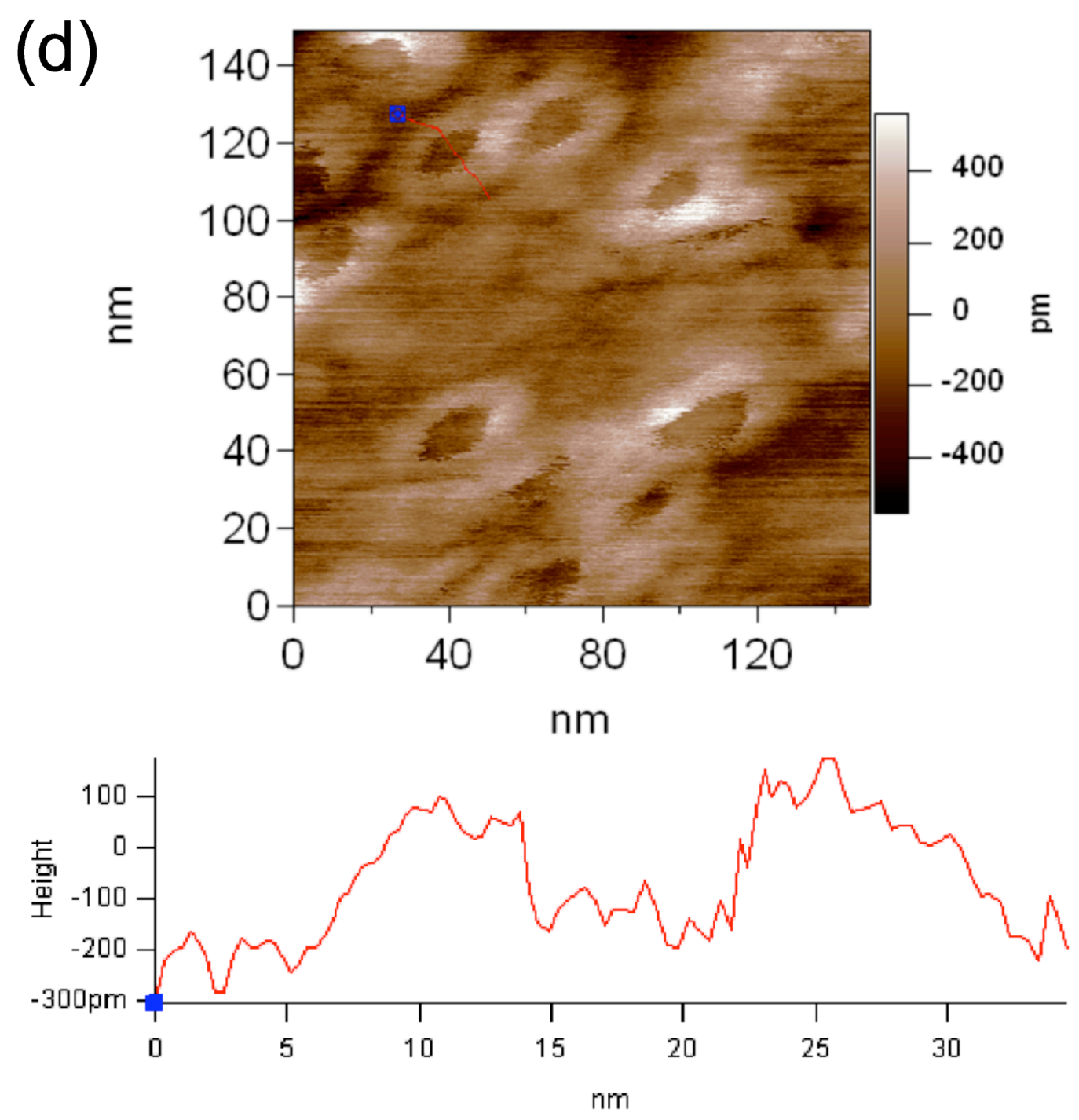